\title{
Determination of Operating Conditions for Hydrogen Peroxide and Hydroxyl Radical Production in Electro-peroxone Process
}

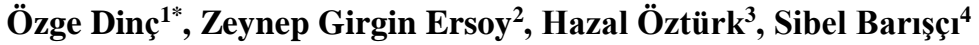 \\ ${ }^{1}$ University of Health Sciences, Institute of Health Science, Department of Biotechnology, Istanbul, Turkey \\ ${ }^{2}$ Department of Molecular Biology and Genetics, ${ }^{3}$ Department of Environmental Engineering, Gebze Technical \\ University, Gebze, Kocaeli, Turkey \\ ${ }^{4}$ Temple University, Collage of Engineering, Water and Environmental Technology Center, Philadelphia, PA, USA \\ *ozge.dinc@sbu.edu.tr
}

Received: 15 February 2018

Accepted: 17 September 2019

DOI: $10.18466 /$ cbayarfbe. 395273

\begin{abstract}
Electro-peroxone (EPO) process is an enhanced ozonation process with a simple installation of electrooxidation apparatus into the ozone reactor. It enables the use of excess oxygen gas caused by inefficient ozone generation by ozone generators. The sparged oxygen is reduced to form hydrogen peroxide $\left(\mathrm{H}_{2} \mathrm{O}_{2}\right)$ on the cathode surface and then the electrogenerated $\mathrm{H}_{2} \mathrm{O}_{2}$ reacts with ozone to form hydroxyl radical $(\mathrm{OH} \bullet$ ). Thus, the highly oxidative species such as $\mathrm{OH} \bullet$ and $\mathrm{H}_{2} \mathrm{O}_{2}$, are produced in the bulk solution. In this study, the effects of operating conditions such as reaction time, ozone flow rate and the applied current on the production of oxidant species were discussed. Response Surface Methodology (RSM) was used for the modeling of reaction conditions. The models employed were both significant for the production of $\mathrm{OH} \bullet$ and $\mathrm{H}_{2} \mathrm{O}_{2}$. Reaction time is the most important factor in the production of oxidants. While the reaction time and ozone flow rate had a synergistic effect on $\mathrm{OH} \bullet$ production, the interaction of the applied flow and the ozone flow rate affected $\mathrm{H}_{2} \mathrm{O}_{2}$ production. Optimum operating conditions were determined maximizing the $\mathrm{OH} \bullet$ concentration. The short reaction time of the process may be preferred because $\mathrm{OH} \bullet$ is inhibited by the electrogenerated $\mathrm{H}_{2} \mathrm{O}_{2}$ at advancing reaction times.
\end{abstract}

Keywords: Advanced oxidation processes, electro-peroxone, hydrogen peroxide, hydroxyl radical, response surface methodology.

\section{Introduction}

Electro-peroxone process (EPO) is an upgraded version of the conventional ozonation process when the electrooxidation mechanism is used in the ozone reactor. Ozone generators have low transformation capacity to form aqueous ozone from the oxygen gas. The excessive oxygen gas in conventional ozonation is utilized to generate hydrogen peroxide $\left(\mathrm{H}_{2} \mathrm{O}_{2}\right)$ in the EPO process. Here, the key point of the process is the usage of carbonbased electrodes such as carbon-polytetrafluoroethylene (carbon-PTFE), carbon felt, and carbon nanotubes for the cathode material [1]. The oxygen is reduced to form hydrogen peroxide on the cathode surface in the conformity with Eq. 1.1:

$\mathrm{O}_{2}+2 \mathrm{H}^{+}+2 \mathrm{e}^{-} \rightarrow \mathrm{H}_{2} \mathrm{O}_{2}$

Then, the electro-generated $\mathrm{H}_{2} \mathrm{O}_{2}$ reacts with $\mathrm{O}_{3}$ to form hydroxyl radical $(\mathrm{OH} \bullet)$ according to Eq. 1.2:

$\mathrm{O}_{3}+\mathrm{H}_{2} \mathrm{O}_{2} \rightarrow \mathrm{OH} \bullet+\mathrm{O}_{2}^{-\bullet}+\mathrm{O}_{2}$

The relative oxidation power of $\mathrm{H}_{2} \mathrm{O}_{2}$ and $\mathrm{OH} \bullet$ is 1.31 and 2.05, respectively [2]. Accordingly, highly oxidative media is formed during EPO process to oxidize target pollutants. The EPO process has been applied for the treatment of organic substances such as oxalic acid [3], 1,4-dioxane [4], amoxicillin [5], Orange II [6], diethyl phthalate [1] and some water matrixes such as laundry wastewater [7], landfill leachate [8], drinking water [9] and secondary effluents of wastewater treatment plants [10]. Most of the papers presented comparable results with conventional ozonation [11] and the removal of target organic substances is improved by the EPO process $[7,12]$. . In addition, the formation of oxidant species during EPO, ozonation and electrooxidation processes was given comparatively [13]. Indeed, the oxidant species (i.e. $\mathrm{OH} \bullet$ and $\mathrm{H}_{2} \mathrm{O}_{2}$ ) were generated in higher concentration during the EPO process than those of ozonation or electrooxidation processes. However, no evaluation has been made on the production of oxidant species in the EPO process, depending on operating conditions. In this paper, the main important factors such as reaction time, ozone flow rate and applied current are evaluated for the production of oxidant species. The formation of $\mathrm{OH} \bullet$ and $\mathrm{H}_{2} \mathrm{O}_{2}$ was observed as dependent parameters in Response Surface Methodology (RSM), 
and the models were developed according to the experimental results.

\section{Materials and Methods}

\subsection{E-peroxone Process Setup}

The EPO system included a reserved Plexiglass reactor, DC power supply, ozone generator and online analyzer for the $\mathrm{H}_{2} \mathrm{O}_{2}$ measurement. The reactor with $2000 \mathrm{ml}$ capacity was installed with electrode plates and ozone diffuser on the bottom of it. Carbon PTFE electrodes (2 pieces) were used as a cathode with the dimension $0.3 \mathrm{x}$ $2 \times 15 \mathrm{~cm}$ of each. Anode electrode was a platinum sheet with the dimension of $0.1 \times 1 \times 15 \mathrm{~cm}$. Sodium sulphate as supporting electrolyte was used in the concentration of $0.05 \mathrm{M}$. Ozone gas fed into the reactor with the desired concentration after becoming a stable trend. DC power supply and the ozone generator were turned on simultaneously for the EPO treatment. The generation of $\mathrm{H}_{2} \mathrm{O}_{2}$ was observed online during the reaction. The $\mathrm{OH} \bullet$ concentration was determined through the terephthalic acid (TA) cumulative protocol [14]. In this case, TA was added to the reactor instead of sodium sulfate to capture the formed $\mathrm{OH} \bullet$ radical in the form of hydroxyterephthalic acid (HTA).

\subsection{Statistical Analysis}

Design expert, version 8.0.4.1 (STAT-EASE Inc., Minneapolis, USA) was operated for the statistical analysis in this study. Box-Behnken design with three independent parameters was established for modeling the production of oxidants in the EPO process. The concentrations of oxidant species (i.e. $\mathrm{OH} \bullet$ and $\mathrm{H}_{2} \mathrm{O}_{2}$ ) were recorded as the responses of the model. The values of the independent parameters and the results of the responses are given in Table 1.

The production of oxidant species was fitted to a general function of the second-order polynomial equation. The employed model of the second order polynomial is:

$$
\mathrm{R}=\beta_{\mathrm{o}}+\sum \beta_{\mathrm{i}} \mathrm{X}_{\mathrm{i}}+\sum \beta_{\mathrm{ii}} \mathrm{X}_{\mathrm{i}}^{2}+\sum \beta_{\mathrm{ij}} \mathrm{X}_{\mathrm{i}} \mathrm{X}_{\mathrm{j}}
$$

where $R$ is the predicted response, $X_{i}$ and $X_{j}$ are independent factors, $\beta_{o}$ is the intercept, $\beta_{i}$ is the linear coefficient, $\beta_{\mathrm{ii}}$ is the quadratic coefficient and $\beta_{\mathrm{ij}}$ is the interaction coefficient.

Table 1. Operating levels of independent parameters.

\begin{tabular}{|c|c|c|c|c|c|}
\hline 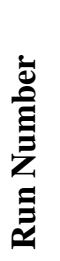 & 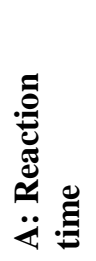 & 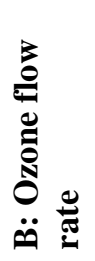 & 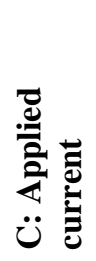 & 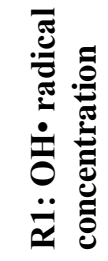 & Oِ \\
\hline & $(\min )$ & (L/h) & (A) & $(\boldsymbol{\mu M})$ & $(\mathrm{mg} / \mathrm{L})$ \\
\hline 1 & 5.00 & 200 & 0.6 & 11.09 & 3508.8 \\
\hline 2 & 5 & 120 & 0.2 & 9.695 & 5997.5 \\
\hline
\end{tabular}

\begin{tabular}{cccccc}
3 & 45 & 200 & 0.6 & 0.020 & 6362.0 \\
4 & 25 & 120 & 0.6 & 3.548 & 5409.5 \\
5 & 45 & 120 & 0.2 & 1.026 & 6498.8 \\
6 & 25 & 120 & 0.6 & 0.046 & 5482.1 \\
7 & 25 & 120 & 0.6 & 0.155 & 4593.5 \\
8 & 45 & 120 & 1.0 & 0.001 & 4124.8 \\
9 & 45 & 40 & 0.6 & 1.567 & 6073.4 \\
10 & 25 & 40 & 1.0 & 0.004 & 3174.6 \\
11 & 25 & 120 & 0.6 & 1.431 & 5070.4 \\
12 & 25 & 40 & 0.2 & 0.456 & 7233.2 \\
13 & 25 & 200 & 1.0 & 0.587 & 4331.6 \\
14 & 5 & 120 & 1.0 & 9.061 & 1405.8 \\
15 & 25 & 200 & 0.2 & 0.595 & 4178.4 \\
16 & 25 & 120 & 0.6 & 0.937 & 4729.3 \\
17 & 5 & 40 & 0.6 & 6.272 & 2813.6 \\
\hline
\end{tabular}

ANOVA analysis was employed to reveal the significance and applicability of each model. Perturbation plots and 3D surface graphs were used to evaluate the effect of the variables on the production of $\mathrm{OH} \bullet$ and $\mathrm{H}_{2} \mathrm{O}_{2}$.

\section{Results and Discussion}

\subsection{The significancy of the employed models}

The model F-ratio (Fisher variation ratio), the probability value (prob $>F)$ and adequate precision are the main indicators donating the significancy and acceptability of the model employed. Statistical values of the employed model obtained from ANOVA analysis are given in Table 2 .

The models employed based on the F- ratio were significant. On the other hand, lack of fit is desired to be non-significant for a fit model. The value of $\mathrm{R}$ square $\left(\mathrm{R}^{2}\right)$ indicates the correlation between the predicted and actual values of parameters. A high value of $\mathrm{R}^{2}$ was acquired for the models of $\mathrm{OH} \bullet$, while a low $\mathrm{R}^{2}$ was obtained in the case of $\mathrm{H}_{2} \mathrm{O}_{2}$.

Table 2. Statistical values of the model employed according to ANOVA Analysis.

\begin{tabular}{|c|c|c|}
\hline Response & $\begin{array}{l}\text { OH・ } \\
\text { production }\end{array}$ & $\begin{array}{l}\mathrm{H}_{2} \mathrm{O}_{2} \\
\text { production }\end{array}$ \\
\hline F value & 18.16 & 11.40 \\
\hline $\begin{array}{l}\text { Significant } \\
\text { model terms* }\end{array}$ & $\mathrm{A}, \mathrm{AB}, \mathrm{A}^{2}$ & $\mathrm{~A}, \mathrm{C}, \mathrm{BC}$ \\
\hline $\begin{array}{l}\text { Lack of fit } \\
\text { significance** }\end{array}$ & $\begin{array}{l}0.24 \\
\text { non-significant }\end{array}$ & $\begin{array}{l}4.22 \\
\text { non-significant }\end{array}$ \\
\hline R square & 0.95 & 0.87 \\
\hline Predicted $\mathrm{R}^{2}$ & 0.84 & 0.46 \\
\hline Adjusted $\mathrm{R}^{2}$ & 0.90 & 0.79 \\
\hline $\begin{array}{l}\text { Adequate } \\
\text { Precision }\end{array}$ & 12.95 & 12.87 \\
\hline
\end{tabular}


It is expected that the difference between predicted and adjusted $\mathrm{R}^{2}$ should be less than 0.2 . In view of that, the differences between them were in reasonable agreement for the models of $\mathrm{OH} \bullet$ production. However, the predicted $\mathrm{R}^{2}$ was also quite low for $\mathrm{H}_{2} \mathrm{O}_{2}$ production. The hydrogen peroxide was the most abundant species in EPO reactions. Hydrogen peroxide concentration increased rapidly in the first minutes of the reaction, and it reached a steady state after a while. Therefore, the $\mathrm{R}^{2}$ value of the model remained relatively low compared with the model of $\mathrm{OH} \bullet$

Adequate precision determines a signal to noise ratio, and a value greater than four is desirable. The entire models employed showed adequate signals. Significant model term of $\mathrm{OH} \bullet$ production was just the reaction time. The synergistic effect of reaction time and ozone flow rate of $\mathrm{OH} \cdot$ production also can be seen from Table 2 . The reaction time and the applied current affected the $\mathrm{H}_{2} \mathrm{O}_{2}$ production individually, and the intersection of the applied current and ozone flow rate had an impact on the production of $\mathrm{H}_{2} \mathrm{O}_{2}$. Eventually, the reaction time was the major parameter that affected all responses.

\subsection{The evaluation of hydroxyl radical production}

Perturbation plot gives the individual effect of the independent parameters on the response. Coded units from -1.000 to 1.000 signify the range between minimum and maximum values of independent parameters. As seen in Figure 1, $\mathrm{OH} \bullet$ concentration was mostly affected by changes in the reaction time (A). The applied current $(\mathrm{C})$ and ozone flow rate (B) had no significant effect on the production of $\mathrm{OH} \bullet$.

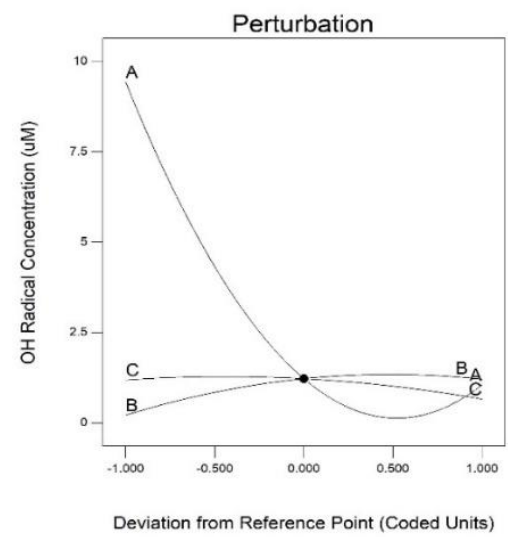

Figure 1. The perturbation plot of the $\mathrm{OH} \cdot$ production (The applied current of 0.6 ampere, the reaction time of $25 \mathrm{~min}$, the ozone flow rate of $120 \mathrm{~L} / \mathrm{h}$ ).

The production of $\mathrm{OH} \bullet$ was seen to be a time-dependent process according to these results. Furthermore, it was also dependent on the reactions between the species produced during the process. At the beginning of the reactions, aqueous ozone and hydrogen peroxide were available in the solution to produce $\mathrm{OH} \bullet$ upon Equation 1.2. Subsequently, $\mathrm{H}_{2} \mathrm{O}_{2}$ was produced excessively in the bulk solution and it inhibited the formation of $\mathrm{OH}$ • Furthermore, hydrogen gas formation on the cathode surface may cause the formation of hydrogen bubbles covering the electrode surface, and this can be resulted in a reduced transfer area. The decrease of A-curve seen in Figure 1 tells about this phenomenon.

The synergistic effect of independent parameters is shown in Figure 2. The applied current did not affect the production of $\mathrm{OH} \bullet$ as seen in Figure 2a. Besides, the interrelation between the applied current and the reaction time was insignificant. The increase of the applied current did not cause to further removal of the organics as reported in the literature $[5,13]$. It is considered that $\mathrm{OH} \bullet$ radical, which provides effective organic abatement, could not produce sufficiently as the applied current increased. On the other hand, the change of ozone flow rate was influential on $\mathrm{OH} \bullet$ production just within shorter reaction time (i.e. 5-20 minutes) as seen in Figure 2b. It is because of that the increase of the ozone flow rate does not state to the formation of aqueous ozone concentration. Ozone is poorly soluble in water and the rate of autodecompsozition of ozone is higher than the rate of mass transfer of the gaseous ozone [15]. In our cases, ozone can transform into the aqueous form from gaseous at the beginning of the reaction, but in time, it was probably decomposed and used for further reactions to generate $\mathrm{OH} \bullet$ radicals.

The ozone flow rate and the reaction time affected synergistically $\mathrm{OH} \bullet$ production. Accordingly, $\mathrm{OH} \bullet$ concentration can be stated as the following equation based on the RSM model.

$\mathrm{OH} \cdot$ concentration $(\mu \mathrm{M})=1.22-4.19 \mathrm{~A}-1.60 \mathrm{AB}+$ $4.02 \mathrm{~A}^{2}$
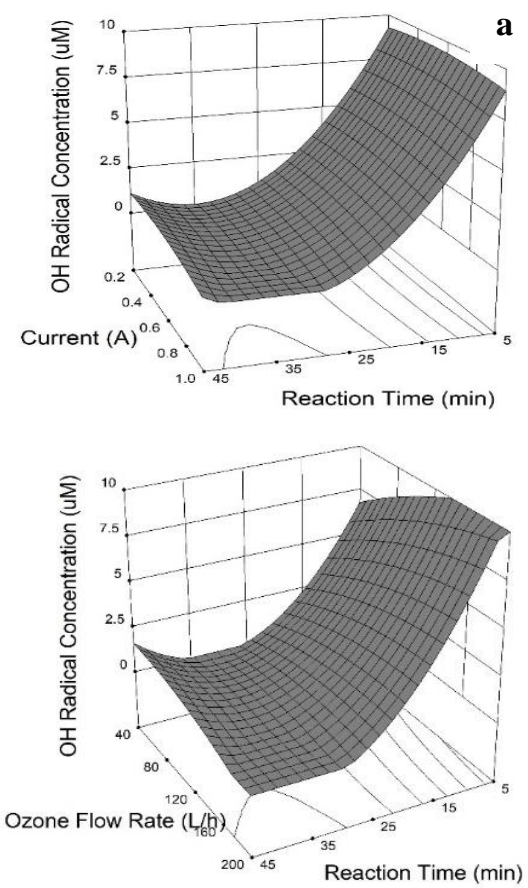

Figure 2. a) The applied current and the re $\mathbf{b}$ n time interrelation b) the ozone flow rate and the reauun time interrelation for the production of $\mathrm{OH} \bullet$. 
If appropriate reaction conditions are to be determined, $\mathrm{OH} \bullet$ radical concentration is desired to be maximized within oxidation processes. According to these results, low reaction time of 5 minutes and ozone flow rate of about $150 \mathrm{~L} / \mathrm{h}$ are found effective to acquire high $\mathrm{OH} \bullet$ concentration.

\subsection{The evaluation of hydrogen peroxide production}

The individual effect of the applied current, reaction time and ozone flow rate of $\mathrm{H}_{2} \mathrm{O}_{2}$ production can be seen in Figure 3. B-curve, namely the ozone flow rate, had no impact on the $\mathrm{H}_{2} \mathrm{O}_{2}$ concentration. Whereas reaction time (A-curve) affected positively, the applied current (Ccurve) showed a negative impact on the production of $\mathrm{H}_{2} \mathrm{O}_{2}$. In other words, the increase in current caused a decrease in the $\mathrm{H}_{2} \mathrm{O}_{2}$ concentration. The higher current accelerated anodic reactions in the bulk solution, and $\mathrm{H}_{2} \mathrm{O}_{2}$ could be decomposed at the anode surface according to Eq. 3.2. Furthermore, the $\mathrm{H}_{2} \mathrm{O}_{2}$ concentration may decrease due to the selfdecomposition of $\mathrm{H}_{2} \mathrm{O}_{2}$ based on Eq.3.3.[16]

$$
\begin{aligned}
& \mathrm{H}_{2} \mathrm{O}_{2} \rightarrow 2 \mathrm{H}^{+}+\mathrm{O}_{2}+2 \mathrm{e}^{-} \\
& 2 \mathrm{H}_{2} \mathrm{O}_{2} \rightarrow 2 \mathrm{H}_{2} \mathrm{O}+\mathrm{O}_{2}
\end{aligned}
$$

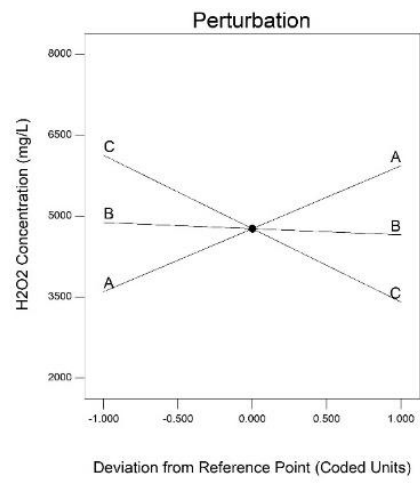

Figure 3. The perturbation plot of the $\mathrm{H}_{2} \mathrm{O}_{2}$ production (The applied current of 0.6 ampere, reaction time of 25 min, ozone flow rate of $120 \mathrm{~L} / \mathrm{h}$ ).

Ozone and the sparged oxygen gases fed into the reactor during the process. The sparged $\mathrm{O}_{2}$ from the ozone generator can be utilized to form $\mathrm{H}_{2} \mathrm{O}_{2}$. The EPO process provides in-situ $\mathrm{H}_{2} \mathrm{O}_{2}$ generation by means of cathodic reduction of $\mathrm{O}_{2}$ on the cathode surface. As seen in Figure $3, \mathrm{H}_{2} \mathrm{O}_{2}$ was generated properly as the time increased by using the sparged $\mathrm{O}_{2}$. Some of the $\mathrm{H}_{2} \mathrm{O}_{2}$ produced was consumed to produce $\mathrm{OH} \bullet$ radical based on Eq. (1.2). However, it is not desired a high concentration of $\mathrm{H}_{2} \mathrm{O}_{2}$ for production of $\mathrm{OH} \bullet$, since $\mathrm{H}_{2} \mathrm{O}_{2}$ can limit $\mathrm{OH} \bullet$ as stated before. On the other hand, the aqueous ozone concentration was also observed as a control parameter during the EPO process (Data not shown). It was not included in the model, because . ozone is consumed in such ways in the EPO system $i$ ) to form $\mathrm{OH} \bullet$ radicals based on Eq. (1.1 and 1.2) ii) to form conjugate base of hydrogen peroxide $\left(\mathrm{HO}_{2}^{-}\right)$(Eq. 3.3) and other radical species (Eq. 3.4 and 3.5). Indeed, ozone concentration covaried by the production of $\mathrm{H}_{2} \mathrm{O}_{2}$ and $\mathrm{OH} \bullet$ during the EPO process. The ozone gaseous fed into the reactor transforms into the aqueous form of ozone and then participates through the aforementioned reactions. Here, the important factor is to provide efficient mass transfer for a gaseous form of ozone to aqueous form by dispersing ozone gaseous in the bubble with an optimum gas flow rate.

$\mathrm{O}_{3}+\mathrm{OH}^{-} \rightarrow \mathrm{HO}_{2}^{-}+\mathrm{O}_{2}$

$\mathrm{HO}_{2}{ }^{-}+\mathrm{O}_{3} \rightarrow \mathrm{OH} \bullet+\cdot \mathrm{O}_{2}{ }^{-}+\mathrm{O}_{2}$

$\mathrm{HO}_{2}^{-}+\mathrm{OH} \bullet \rightarrow \cdot \mathrm{O}_{2} \mathrm{H}+\mathrm{OH}^{-}$

The synergistic effect of independent parameters is shown in Figure 4. There was no significant interaction between the applied current and reaction time as seen in Figure 4a. However, the increase in the time provided an increase in $\mathrm{H}_{2} \mathrm{O}_{2}$ concentration for all values of the applied current. The increment in $\mathrm{H}_{2} \mathrm{O}_{2}$ was more notable for higher applied current values.
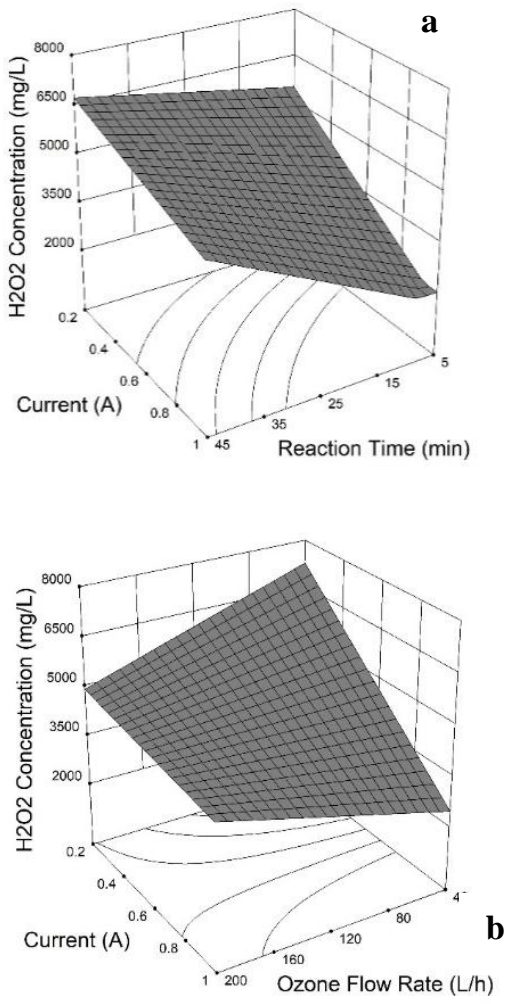

Figure 4. a) The applied current and reaction time interrelation b) The applied current and ozone flow rate interaction for the production of $\mathrm{H}_{2} \mathrm{O}_{2}$.

Figure $4 \mathrm{~b}$ shows the interrelation between the applied current and ozone flow rate. The lower values of these independent parameters provided a higher production of $\mathrm{H}_{2} \mathrm{O}_{2}$. When the ozone flow rate is low, adequate ozone gaseous transforms into aqueous ozone. Eventually, the model equation for the $\mathrm{H}_{2} \mathrm{O}_{2}$ concentration became as below;

$\mathrm{H}_{2} \mathrm{O}_{2}$ concentration $(\mathrm{mg} / \mathrm{L})=4763.97+1166.68 \mathrm{~A}-$ $1358.88 \mathrm{C}+1052.95 \mathrm{BC}$ 
Hydrogen peroxide is produced electrochemically on the cathode surface in the EPO process. Its concentration increased sharply and exceeded $2000 \mathrm{mg} / \mathrm{l}$ within 5 minutes of the reaction at any other operating conditions. However, the huge amount of $\mathrm{H}_{2} \mathrm{O}_{2}$ is not desired to avoid the inhibition of $\mathrm{OH} \bullet$ production. Therefore, short reaction time with an average ozone flow is also convenient for the $\mathrm{H}_{2} \mathrm{O}_{2}$ production.

\section{Conclusion}

EPO process is a new and superior oxidation technique. This has been successfully applied to remove some contaminants from the water. In this paper, it has been considered that how $\mathrm{OH} \bullet$ and $\mathrm{H}_{2} \mathrm{O}_{2}$ formation dominate the oxidation features of the EPO process. The concentrations of these oxidants may vary depending on operating conditions such as reaction time, ozone flow rate and applied current. The production of $\mathrm{OH} \bullet$ and $\mathrm{H}_{2} \mathrm{O}_{2}$ was modeled through the RSM, and operating conditions were discussed. The models employed for $\mathrm{OH} \bullet$ and $\mathrm{H}_{2} \mathrm{O}_{2}$ production were statistically significant. Mostly, reaction time governed the oxidation features of the EPO process. According to the results, reaction time and ozone flow affected the $\mathrm{OH} \cdot$ production efficiency together. The applied current and ozone flow rate had a synergistic effect of $\mathrm{H}_{2} \mathrm{O}_{2}$ production. The production $\mathrm{OH} \cdot$ peaked in the first minutes of reaction, and then decreased, due to the inhibition effect of excessive $\mathrm{H}_{2} \mathrm{O}_{2}$. Because of abundant $\mathrm{H}_{2} \mathrm{O}_{2}$ generation, $\mathrm{OH} \bullet$ production is the main factor to obtain desired operating conditions. Due to the inhibition and decomposition of oxidant species during the subsequent reaction times, a short reaction time of the process may be preferred.

EPO process enables the production of major oxidant species in itself within a short time. The process is also cost-effective due to utilization of excessive oxygen during ozone generation. EPO process can take the place of conventional ozonation with a simple system change in the near future.

\section{Acknowledgement}

The authors would like to thank The Scientific and Technological Research Council of Turkey (TUBITAK) for their financial support (Grant Number 116Z572).

\section{Author's Contributions}

Özge Dinç: Drafted and wrote the manuscript, developed the model and interpreted the results.

Zeynep Girgin Ersoy: Supplied all the equipment and chemicals and designed the experimental setup.

Hazal Öztürk: Performed the experiments and reported the results.

Sibel Barıșçı: Assisted in data interpretation and helped in manuscript preparation.

\section{Ethics}

There are no ethical issues after the publication of this manuscript.

\section{References}

1. Hou M., Chu Y., Li X., Wang H., Yao W., Yu G., Murayama S., Wang Y. 2016. Electro-peroxone degradation of diethyl phthalate: Cathode selection, operational parameters, and degradation mechanisms. Journal of Hazardous materials; 319: 61-68.

2. Munter R. 2001. Advanced oxidation processes-current status and prospects. Proceedings of the Estonian Academy of Sciences. Chemistry; 50 (2): 59-80.

3. Wang H., Yuan S., Zhan J., Wang Y., Yu G., Deng S., Huang J., Wang B. 2015. Mechanisms of enhanced total organic carbon elimination from oxalic acid solutions by electro-peroxone process. Water Research; 80: 20-29.

4. Wang H., Bakheet B., Yuan S., Li X., Yu G., Murayama S., Wang Y. 2015. Kinetics and energy efficiency for the degradation of 1, 4-dioxane by electro-peroxone process. Journal of Hazardous materials; 294: 90-98.

5. Guo W., Wu Q.-L., Zhou X.-J., Cao H.-O., Du J.-S., Yin R.-L., Ren N.-Q. 2015. Enhanced amoxicillin treatment using the electroperoxone process: key factors and degradation mechanism. RSC Advances; 5 (65): 52695-52702.

6. Bakheet B., Yuan S., Li Z., Wang H., Zuo J., Komarneni S., Wang Y. 2013.Electro-peroxone treatment of Orange II dye wastewater. Water Research; 47 (16): 6234-6243.

7. Turkay O., Barış̧ı S., Sillanpää M. 2017. E-peroxone Process for the Treatment of Laundry Wastewater: A Case Study. Journal of Environmental Chemical Engineering; 5(5): 4282-4290.

8. Li Z., Yuan S., Qiu C., Wang Y., Pan X., Wang J., Wang C., Zuo J. 2013. Effective degradation of refractory organic pollutants in landfill leachate by electro-peroxone treatment. Electrochimica Acta; 102: 174-182.

9. Li Y., Shen W., Fu S., Yang H., Yu G., Wang Y. 2015. Inhibition of bromate formation during drinking water treatment by adapting ozonation to electro-peroxone process. Chemical Engineering Journal; 264: 322-328.

10. Yao W., Wang X., Yang H., Yu G., Deng S., Huang J., Wang B., Wang Y. 2016. Removal of pharmaceuticals from secondary effluents by an electro-peroxone process. Water Research; 88: 826-835.

11. Li X., Wang Y., Yuan S., Li Z., Wang B., Huang J., Deng S., Yu G., 2014. Degradation of the anti-inflammatory drug ibuprofen by electro-peroxone process. Water Research; 63: 81-93.

12. Li X., Wang Y., Zhao J., Wang H., Wang B., Huang J., Deng S., Yu G. 2015. Electro-peroxone treatment of the antidepressant venlafaxine: Operational parameters and mechanism. Journal of hazardous materials; 300: 298-306.

13. Turkay O., Barışçı S., Öztürk B., Öztürk H., Dimoglo A. 2017. Electro-Peroxone Treatment of Phenol: Process Comparison, the Effect of Operational Parameters and Degradation Mechanism. Journal of The Electrochemical Society; 164 (9): E180-E186.

14. Milan-Segovia N., Wang Y., Cannon F. S., Voigt R. C., Furness J. C 2007. Comparison of hydroxyl radical generation for various advanced oxidation combinations as applied to foundries. Ozone: Science and Engineering; 29 (6): 461-471.

15. Roth J. A., Sullivan D. E. 1981. Solubility of ozone in water, Industrial \& Engineering Chemistry Fundamentals; 20 (2): 137-140.

16. Wang Y. The Electro-peroxone Technology as a Promising Advanced Oxidation Process for Water and Wastewater Treatment. In: In: Zhou M., Oturan M., Sirés I. (eds) Electro-Fenton Process. The Handbook of Environmental Chemistry, vol 61. Springer, Singapore, 2017. 